\title{
Complex approach to the study of modern concrete characteristics
}

\author{
Maria Dmitrieva ${ }^{1, *}$, Vladimir Leitsin ${ }^{2}$, Anastasiia Sharanova ${ }^{1}$ and Alexander Tovpinets ${ }^{2}$ \\ ${ }^{1}$ Immanuel Kant Baltic Federal University, Institute of Environmental Management, Urban \\ Development and Spatial Planning, 236016 Nevskogo str. Kaliningrad, Russia \\ ${ }^{2}$ Immanuel Kant Baltic Federal University, Laboratory of Fundamental and Applied Material \\ Sciences, 236016 Nevskogo str. Kaliningrad, Russia
}

\begin{abstract}
The possibility of complex experimental study of the structure and properties of modern multicomponent concretes combining the influence of mechanical activation of the initial powder components of building mixtures, the rheology of concrete solutions, the structure of the concrete mixture, the distribution of various components and pores, the nature of damage and destruction at various stages of concrete strength testing is considered. The classical set of experimental methods for studying the rheological characteristics and strength of concretes at various setting stages is supplemented by studies of the concrete structure using Xray computed tomography. The developing approach allows to solve the fundamental problems of building material science of concrete.
\end{abstract}

\section{Introduction}

Modern concrete is made from multicomponent building mixtures modified in the intensive mechanical activation process [1] with additives providing the required rheological properties and strength kinetics. Mechanical activation provides an increase in the rate of concrete setting and more complete use of cementitious properties of cement $[2,3]$. With the mechanical activation of cement, the concrete strength increases at the initial time of hardening [4], which is a necessary condition for the implementation of additive technologies in construction [5].

In this paper, the components of the fine-grained concrete mixture were subjected to mechanical co-activation in a high-speed ball mill to assess the effect of mechanical activation conditions on the kinetics of setting processes and the strength of concrete. In materials science, X-ray tomography is used as a method for nondestructive testing of the material state, in particular in the concrete industry, tomography is suitable for determining the structure of concretes, microcracks, internal fractures, and investigating the distribution of pores and aggregate particles. Computed X-ray tomography provides construction of a microstructure model for cement paste, allows to study the development of hydration processes of cements and build predictions for the formation of mechanical characteristics and failure conditions $[6,7]$. Computed tomography is actively used for study of formation

\footnotetext{
* Corresponding author: dmitrieva_m@inbox.ru
} 
and distribution of pores in foamed and lightweight concrete [8, 9], for the analysis of microstructural characteristics of lightweight concrete samples with various aggregates [10], for the development of three-dimensional mesoscale models of concrete finite elements [11]. Compared with standard 2D radiography methods, the construction of 3D models of multicomponent concretes (computer tomograms) is promising for studying the fundamental mechanisms of formation of the modern concrete structure and properties.

\section{Methods}

For the preparation of concrete mixture the following materials were used: 1) Portland cement Eurocem 500 super, CEM I 42.5 N, LLC "Petersburg cement"; 2) construction sand: fraction $0.315 \mathrm{~mm}$, deposit: Kaliningrad region; 3) microsilica, production: Poland 4) highly active metakaolin (white), production: Chelyabinsk region, GC "Synergo"; 5) polypropylene fiber (fiber length $12 \mathrm{~mm}$, thickness $35 \mu \mathrm{m}$ ), production: Russia; 6) hyperplasticizer based on carboxylates «Stachement 1267», production: Poland. The consumption of materials is given in Table 1 .

Table 1. Consumption of materials per $1 \mathrm{~m}^{3}$.

\begin{tabular}{|c|c|c|c|c|c|c|c|}
\hline $\begin{array}{c}\text { Water/ } \\
\text { Ceme } \\
\mathrm{nt}\end{array}$ & $\begin{array}{c}\text { Cement, } \\
\mathrm{kg} / \mathrm{m}^{3}\end{array}$ & $\begin{array}{c}\text { Sand, } \\
\mathrm{kg} / \mathrm{m}^{3}\end{array}$ & $\begin{array}{c}\text { Water, } \\
1 / \mathrm{m}^{3}\end{array}$ & $\begin{array}{c}\text { Microsil } \\
\text { ica, } \\
\mathrm{kg} / \mathrm{m}^{3}\end{array}$ & $\begin{array}{c}\text { Metakaolin, } \\
\mathrm{kg} / \mathrm{m}^{3}\end{array}$ & $\begin{array}{c}\text { Polypropylene } \\
\text { fiber, } \mathrm{kg} / \mathrm{m}^{3}\end{array}$ & $\begin{array}{c}\text { Stachement } \\
1267,1 / \mathrm{m}^{3}\end{array}$ \\
\hline 0,66 & 545,3 & 1168 & 360 & 156 & 78 & 1,2 & 11,7 \\
\hline
\end{tabular}

In this study, samples of concrete mixtures with activated and non-activated components were made, for each mixture setting times and compressive strengths were determined at early hardening times. Mechanical activation of the concrete mixture components was carried out in a high-speed ball mill Retsch EMax using corundum balls as milling bodies (activated material/ milling bodies $=1 / 2$ ). Co-activation of cement and sand was selected as an activation mode at a speed of $750 \mathrm{rpm}$ for 5 minutes. The setting times were determined in accordance with GOST 310.3-76 using the Vicat test method. Cubic shape samples of the concrete mixtures were made and were tested for compressive strength at the age of 3, 4.5, 6 and 7.5 hours. The internal structure and character of the destruction of the samples were analyzed using X-ray computed tomography on YXLON Y. Cheetah apparatus.

\section{Results}

\subsection{Setting times}

The results of measuring the setting times for mixtures with non-activated and activated components are given in Table 2.

Table 2. Setting times.

\begin{tabular}{|c|c|c|}
\hline Composition (components) & $\begin{array}{c}\text { Start of setting (according to } \\
\text { GOST 310.3-76) }\end{array}$ & $\begin{array}{c}\text { End of setting (according to } \\
\text { GOST 310.3-76) }\end{array}$ \\
\hline Non-activated & $2 \mathrm{~h} 30 \mathrm{~min}$ & $3 \mathrm{~h} 50 \mathrm{~min}$ \\
\hline Activated & $1 \mathrm{~h} 20 \mathrm{~min}$ & $3 \mathrm{~h} 20 \mathrm{~min}$ \\
\hline
\end{tabular}

Co-activation of cement and sand gives a significant reduction in the beginning of setting the concrete mixture, which is especially valuable for the mixtures used in additive technologies in construction. 


\subsection{Study of strength set}

The samples-cubes measuring $20 \times 20 \times 20 \mathrm{~mm}$ were tested for compressive strength on an Instron Electropuls E1000 test machine. The test results are shown in Table 3.

Table 3. Strength test results.

\begin{tabular}{|c|c|c|c|c|c|c|c|c|}
\hline \multirow{2}{*}{$\begin{array}{c}\text { Composition } \\
\text { components) }\end{array}$} & \multicolumn{4}{|c|}{ Destructive force, $\mathrm{N}$ Compressive strength, MPa } \\
\cline { 2 - 9 } & $3.5 \mathrm{~h}$ & $6 \mathrm{~h}$ & $7.5 \mathrm{~h}$ & $3 \mathrm{~h}$ & $4.5 \mathrm{~h}$ & $6 \mathrm{~h}$ & $7.5 \mathrm{~h}$ \\
\hline Non-activated & 85,7 & 172,6 & 207,1 & 237,6 & 0,21 & 0,43 & 0,52 & 0,59 \\
\hline Activated & 116,7 & 210,0 & 270,9 & 346,0 & 0,29 & 0,53 & 0,68 & 0,87 \\
\hline \multicolumn{4}{|c|}{ Strength increase } & $38 \%$ & $23 \%$ & $30,8 \%$ & $47,5 \%$ \\
\hline
\end{tabular}

The strength tests of samples with non-activated and activated components showed that mechanical activation provides a significant increase in strength in the early stages of hardening, and the method of co-activation of cement and sand is effective and can be used to increase the strength of the concrete mixture in the first hours after preparation. This ensures the applicability of the investigated concrete mixes for the form-free forming of building structures by additive technologies.

\subsection{X-ray tomography}

$\mathrm{X}$-ray computed tomography provides construction of a 3D model of heterogeneous bodies based on the results of 2D X-ray diffraction patterns obtained during the rotation of the test sample placed between the source and the X-ray detector.

Figure 1 shows images of the appearance of the 3D model of the initial sample of concrete and one of its sections.

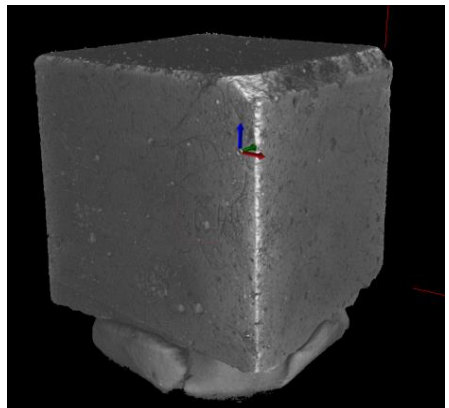

a) appearance of the sample

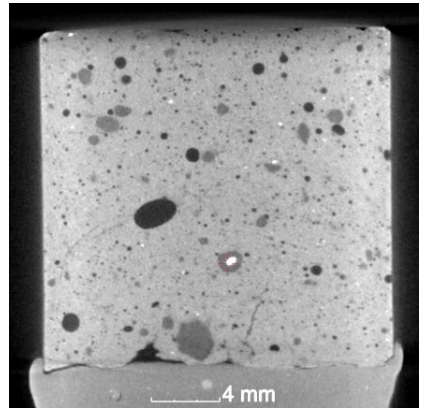

b) frontal section of the sample

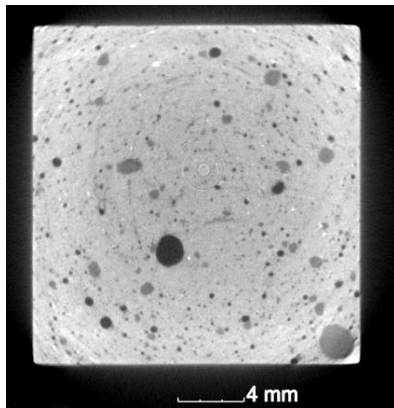

c) transverse section of the sample

Fig.1. 3D model of the initial sample of concrete and its front and cross sections before loading.

The 3D model was reconstructed from the results of the distribution of the $\mathrm{x}$-ray density of the various sections of the sample. The advantages of computed tomography include the possibility of constructing any interesting cross-section of the test sample.

After the compression tests, the destroyed samples with activated components were examined on a tomograph to determine the nature of the destruction, depending on the time of hardening. Images of the internal structure of a concrete mixture samples with activated components before and after application of the load at different time intervals are shown in Figure 2.

On the images obtained through a tomograph, the transition from plastic to brittle fracture of hardening concrete samples is traced. Samples tested 3 hours after manufacture have a plastic fracture character, clear cracks and fractions on the faces of the specimen can be traced. By 4.5 hours of hardening there are signs of brittle fracture, and by 7.5 hours the 
faces of the sample are covered with a grid of small cracks during the fracture, and there are also many cracks and microcracks inside the sample.

a) at the age of

$3 \mathrm{~h}$

b) at the age of

$4.5 \mathrm{~h}$

c) at the age of

$6 \mathrm{~h}$

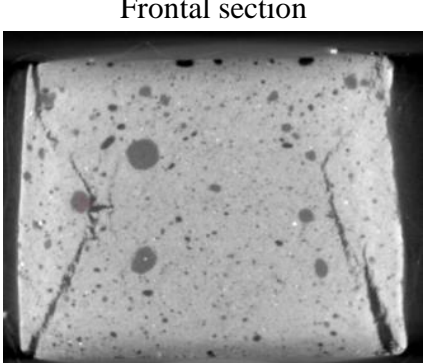

\section{Transverse section}
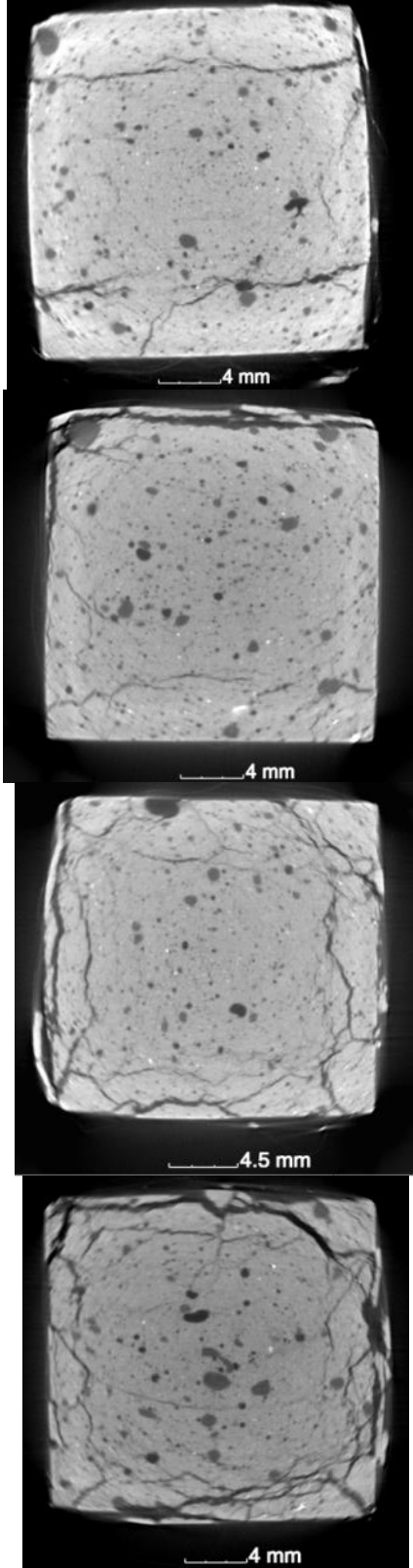

Fig. 2. Images of the internal structure of the samples.

\section{Discussion}

Mechanical activation of the components of dry construction mixtures leads to a reduction of the setting time of concrete mixes, increasing the speed of strength set and improving the strength characteristics of concrete. This indicates the importance of mechanical activation 
to ensure the conditions of applicability of concrete mixtures for additive construction technologies. It has been established that co-activation of cement and sand reduces the setting time of the mixture from 2 hours 30 minutes to 1 hour 20 minutes, gives a strength increase of $23-47.5 \%$ in the first hours after manufacturing. Images obtained through computed tomography give clear images of the internal structure of the concrete mix, providing an opportunity to trace the implementation of various mechanisms of damage and destruction.

The use of modern experimental base of building materials science allows carrying out complex researches of rheological, mechanical and structural characteristics of modern concretes, solving fundamental problems of transition to the modern technological way of the construction industry.

\section{References}

1. V.I. Kalashnikov, Effective high-strength and ordinary concrete: monograph (Privolzhsky House of Knowledge, Penza, 2015)

2. A.V. Andreeva, N.N. Davidova, O.H. Burenina, New materials and technologies in the Arctic, 222 (2014)

3. G.A. Gurianov, E.A. Klimenko, O.Y. Vasilyeva, Transp. Transp. cons. Ecology, 1, 23 (2015)

4. Y.R. Krivoborodov, D.A. Yasko, New sc.: probl. and prosp. 3, 105 (2015)

5. N. I. Vatin, Constr. of un. Build. and struct. 1(52), 27 (2017)

6. M. Zhang, A.P. Jivkov, Comp. Part B: Eng. 88, 64 (2016)

7. E.A. Lavrov, C. Panduro, M. Torsæter, En. Proc. 114, 5109 (2017)

8. T. Nguyen, A. Ghazlan, A. Kashani, S. Bordas, T. Ngo, Constr. and Build. Mat. 188, 583 (2018)

9. H. Lu, E. Alymov, S. Shah, K. Peterson, Constr. and Build. Mat. 152, 467 (2017)

10. S.-Y. Chung, M.A. Elrahman, D. Stephan, P.H. Kamm, Constr. and Build. Mat. 189, 314 (2018)

11. Y. Huang, Z. Yang, W. Ren, G. Liu, C. Zhang, Int. J. of Sol. and Str. 67-68, 340 (2015) 